\title{
¿LA PRIMERA CAPILLA SACRAMENTAL EN LA ANDALUCÍA DEL SIGLO XVI? LA PARROQUIA DE MEDINA SIDONIA (CÁDIZ) Y LA GESTACIÓN DE UN PROYECTO PIONERO \\ JAVIER GONZÁLEZ TORRES \\ FUNDACIÓN VICTORIA - UNIVERSIDAD DE MÁLAGA
}

\begin{abstract}
RESUMEN: En paralelo a los debates conciliares de Trento, Andalucía vive una oleada de fervor eucarístico. Los recursos expresivos del arte se articulan en pro de la materialización plástica de esos conceptos abstractos, entendiéndose cual medio adecuado para la instrumentalización propagandística; interrelación que se completa desde la aplicación teórica de la escolástica medieval, combinada con ciertas prácticas cultuales de raigambre popular. Hacia mediados del siglo XVI va a construirse la que posiblemente sea la primera capilla sacramental del territorio andaluz, en la parroquia de santa María La Coronada, de Medina Sidonia (Cádiz). Una serie de circunstancias históricas e intereses particulares constituyen la génesis de una obra pionera que, sin planteárselo, marcará la senda constructiva de otros espacios análogos posteriores.
\end{abstract}

PALABRAS CLAVE: Reforma católica, Andalucía, arquitectura religiosa, capilla sacramental, iconografía

\section{THE FIRST SACRAMENTAL CHAPEL IN ANDALUSIA OF THE $16^{\mathrm{TH}}$ CENTURY? THE PARISH OF MEDINA SIDONIA (CÁDIZ) AND THE PROGRESSION OF A PIONNER PLAN}

\begin{abstract}
As conciliar debates were happening in Trento, Andalusia experienced a fever of Eucharistic enthusiasm. Expressive artistic resources were used in order to achieve the graphic materialization of the abstract concepts derived from this fervor, which also served as a means of propaganda spreading. This favored the application of medieval scholastic theology combined with certain customs of popular roots. The middle of the sixteenth century saw the construction of a chapel which is allegedly the first sacramental chapel in the Andalusian territory. It was built within the Parish of Santa María La Coronada in Medina Sidonia (Cádiz). A series of historic circumstances and personal interest strongly affected the origins of this ground-breaking architectural work which unwillingly lead the way for the construction of subsequent similar spaces.
\end{abstract}

KEYWORDS: Catholic Reformation, Andalusia, Religious Architecture, Sacramental Chapel, Iconography

Recibido: 01-06-2018/Aceptado: 18-07-2018 
La anexión del Reino de Granada a la Corona de Castilla supone el final del largo proceso de reunificación territorial y político de la Península, en el que va implícito el programa de ‘cristianización' de los últimos bastiones islámicos. La puesta en práctica de una política religiosa sin concesiones, fuertemente jerarquizada, en la que Estado e Iglesia ejercen sus mecanismos de control, caracterizan los comienzos del siglo XVI junto a cuestiones de índole práctica, económica o etnográfica. Con estos cimientos, la construcción del monolítico Estado moderno español sirve de ejemplo para las monarquías europeas, empeñadas desde tiempo anterior en establecer en el Mediterráneo una nueva frontera capaz de taponar cualquier posible intento de revolución/ocupación de origen musulmán.

De crucial importancia son las costumbres, usos y devociones que la propia Iglesia venía impulsando como consecuencia de la adecuación a los nuevos tiempos, intensificadas especialmente en las recién creadas diócesis del oriente andaluz. De igual manera, el contexto cultural en el que se desenvuelve el propio proceso bélico y posterior repoblación, discurre en paralelo a la proyección y difusión de ideas humanistas; un proceso reformador que lidera el cardenal Cisneros y que se completa desde la cátedra prima de Teología de la universidad de Salamanca. En sus aulas se forman un elevado número de personalidades, convertidas tiempo después, en los prelados más sobresalientes del episcopado español.

La educación de los laicos a través de la oración y las prácticas devotas es uno de los objetivos permanentes de la pastoral ejercida por las órdenes mendicantes, responsables de la adopción de posturas militantes en el terreno de la religiosidad popular. Junto a la predicación en sí misma, la promoción del asociacionismo en torno al cuerpo y la sangre de Cristo resulta clave para concretizar determinadas prácticas comunitarias que requieren, de inmediato, su proyección y materialización artísticas ${ }^{1}$.

La conjugación de todas estas premisas supone el aporte teórico fundamental a partir del cual tienen lugar en territorio andaluz distintas iniciativas constructivas, ligadas al terreno de la praxis arquitectónica religiosa. La evolución y adecuación de espacios a cuestiones cultuales, simbólicas e iconográficas constituyen una las más singulares aportaciones creativas, coincidiendo con los albores de una etapa distinta: la Renovación católica; gran parte de la misma queda ligada a la adaptación y asunción de planteamientos que marcan un antes y un después.

\footnotetext{
${ }^{1}$ Cf. GONZÁLEZ TORRES, Javier: La Capilla sacramental en el Barroco andaluz: espacio, simbolismo e iconografia (siglos XVT-XV III). Málaga, Universidad, 2016. Tesis doctoral disponible en: https://riuma.uma.es/xmlui/handle/10630/12832
} 


\section{La parroquia de Medina Sidonia o la catedral que nunca fue}

La pobreza espiritual de la diócesis de Cádiz es constante desde finales del siglo XV. La capital vive una situación anómala pese a su importancia geoestratégica: la escasa dotación con la que cuentan sus prebendados, el mal estado de las edificaciones causado por el salitre, la ausencia de parroquias y monasterios en la trama urbana, las particulares condiciones atmosféricas que lastran los cultivos o el estar siempre expuestos a ataques berberiscos; a ello que hay que añadir la reducida extensión territorial del obispado y los continuos pleitos con la sede arzobispal de Sevilla a cuenta de los linderos. El religioso que asumiera la prelatura gaditana se exponía a estas cuestiones, de ahí que la residencia de los mismos en la diócesis fuese mínima o, en todo caso, se asentasen en Medina Sidonia o Chiclana.

Así, la presencia del cabildo catedralicio a partir de 1472 en la localidad asidonense, capital de la comarca de la Janda, se convierte en permanente. Una acción que cuenta con el respaldo del II duque de Medina Sidonia, Enrique de Guzmán quien, aprovechando las circunstancias, se ofrece para impulsar la renovación de la fábrica del principal templo parroquial y adaptar tanto sus espacios interiores como su imagen externa al rango catedralicio $^{2}$. Aunque los canónigos fueron variando sus decisiones sobre la estancia en la localidad de acuerdo a cuestiones nobiliarias o a mandatos pontificios, se tiene constancia que, a partir de 1514, se inician las obras de construcción de la nueva iglesia sobre una planta de salón, orientada de este a oeste, con tres naves - la central más ancha que las laterales- y cabecera poligonal. Por analogía con otras construcciones alzadas en el Puerto de santa María y Arcos de la Frontera, la mano del maestro Alonso Rodríguez y su equipo de canteros $^{3}$ podría estar presente [Imagen 1].

El proceso constructivo se dilató en exceso, culminándose en la siguiente centuria. La espacialidad alcanzada en su interior y la impronta monumental de la capilla mayor, confieren al conjunto, cuanto menos, la imagen de poderosa colegiata. A ello contribuye la construcción del retablo principal, una enorme máquina lignaria que se contrata en 1533 al entallador Andrés López del Castillo y que, tras pasar distintos avatares, se culmina hacia

\footnotetext{
${ }^{2}$ Existía desde finales del siglo XIV una iglesia que, en clave mudéjar, se alzó en paralelo a otros inmuebles religiosos. Ésta vendría a sustituir a la primitiva mezquita que, desde 1264, se adaptó al culto cristiano. De igual manera, bajo los planes del ducado asidonense subyace la enemistad manifiesta con el marqués de Cádiz, Rodrigo Ponce de León, en una lucha nobiliaria enquistada por la ‘señorialización' tanto de tierras y riquezas como de, incluso, los canónigos y demás dignidades eclesiásticas, a los que pretenden proteger. Víd. SÁNCHEZ HERRERO, José: "La Iglesia de Cádiz en el paso del siglo XV al XVI", Estudios de Historia y de Arqueología medievales X. Cádiz, Universidad, 1994, pp. 160-162.

3 ALONSO RUIZ, Begoña (Coord.): Los últimos arquitectos del Gótico. Madrid, Elecé, 2010, pp. 271-362.
} 
1575 con la participación, entre otros, de los escultores Juan Bautista Vázquez y Melchor Turín ${ }^{4}$. De igual manera, el alto número de canónigos, clérigos, diáconos, subdiáconos y menoristas hubieron de contribuir al esplendor litúrgico de las celebraciones religiosas, recibiendo continuos elogios por parte de visitadores y prelados ${ }^{5}$. No en vano, la implementación y desarrollo de fórmulas rituales unitarias a partir de la segunda mitad del siglo XVI sería práctica obligatoria en todos los recintos religiosos del orbe católico, al adoptar el mismo Brevario y Misal con el que desarrollar el Oficio Divino.

\section{Imagen 1}

\section{Vista exterior actual de la parroquia de Santa María La Coronada, de Medina Sidonia (Cádiz).}

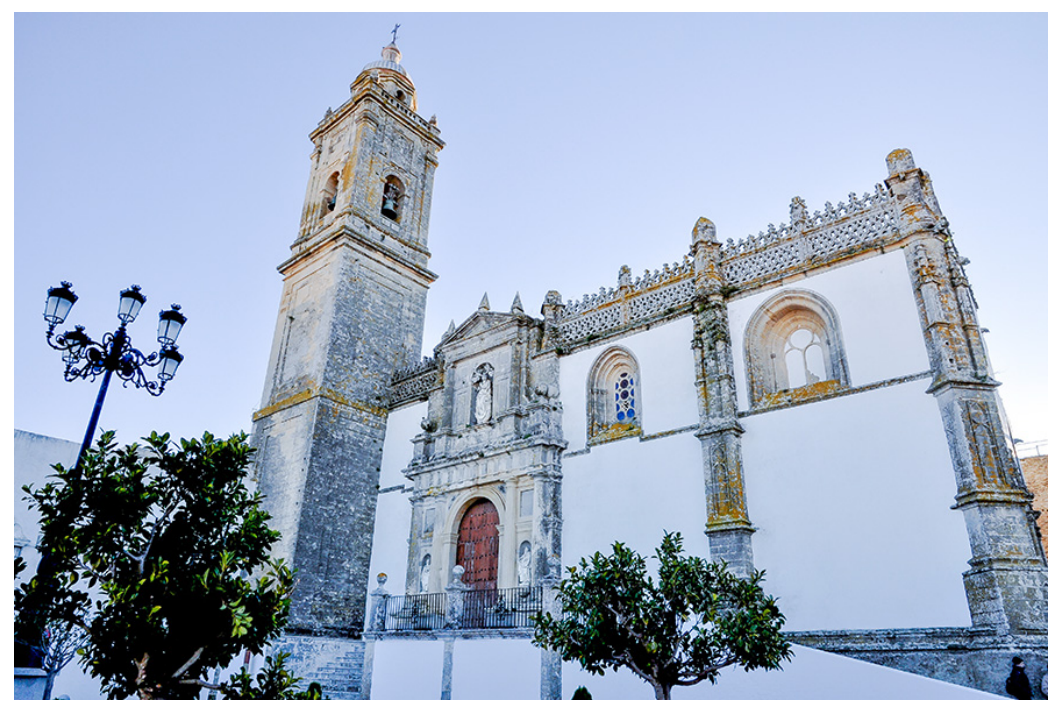

Foto del autor.

Así que, en esa ambientación pre y post-conciliar, esas mismas dignidades eclesiásticas impulsaron la construcción de un espacio dedicado al culto eucarístico, descentralizando las prácticas que de éste derivan de las verificadas en la capilla mayor. La religiosidad popular y sus particulares costumbres serían también objeto de atención, pero no solo por parte de los religiosos responsables, sino también, por los promotores privados ${ }^{6}$. En este sentido, el VI duque, Juan Alonso Pérez de Guzmán, obtiene el 6 de septiembre de

\footnotetext{
${ }^{4}$ Datos recogidos por: SANCHO CORBACHO, Heliodoro: Arte sevillano de los siglos XVI y XVII. Sevilla, Universidad, 1931; y LÓPEZ MARTÍNEZ, Celestino: Desde Jerónimo Hernández hasta Martínez Montañés. Notas para la Historia del Arte. Sevilla, Rodríguez, Giménez y C. ${ }^{\text {., }} 1929$.

${ }^{5}$ MARTÍNEZ Y DELGADO, Francisco: Historia de la ciudad de Medina Sidonia que dejó inédita el Dr. ... Cádiz, Revista Médica, 1799-1875, pp. 195-196.

${ }^{6}$ GALÁN PARRA, Isabel: "El linaje y los Estados señoriales de los duques de Medina Sidonia a comienzos del siglo XVI”, España medieval 11. Madrid, Universidad Complutense, 1988, p. 72.
} 
1541 una Bula firmada por Pablo IV para erigir tanto en Sanlúcar -sede del ducado- como en las tierras integrantes de la casa ducal, cofradías dedicadas a la veneración sacramental que, de inmediato, quedarían agregadas a la de la Minerva de Roma ${ }^{7}$. Motivo más que suficiente para la adhesión del linaje a la corriente defensora de la presencia real de Cristo en la Eucaristía $^{8}$ y la instrumentalización del concepto por parte de una Iglesia cada vez más militante. Una línea de actuación que se refrenda con el encargo de una custodia de asiento, en 1565, a los plateros Juan Tercero y Francisco de Alfaro destinada a la anual procesión del Corpus Christi [Imagen 2]. Es de esta manera como las bases cultuales y canónicas quedaban fijadas al imaginario colectivo, siendo solo cuestión de tiempo la construcción de un altar propio en el que desarrollar las prácticas eucarísticas.

\section{Imagen 2}

Custodia del Corpus Christi. Ostensorio de Juan Tercero y templete de Francisco de Alfaro (1575). Exposición actual en la sacristía de la parroquia asidonense.

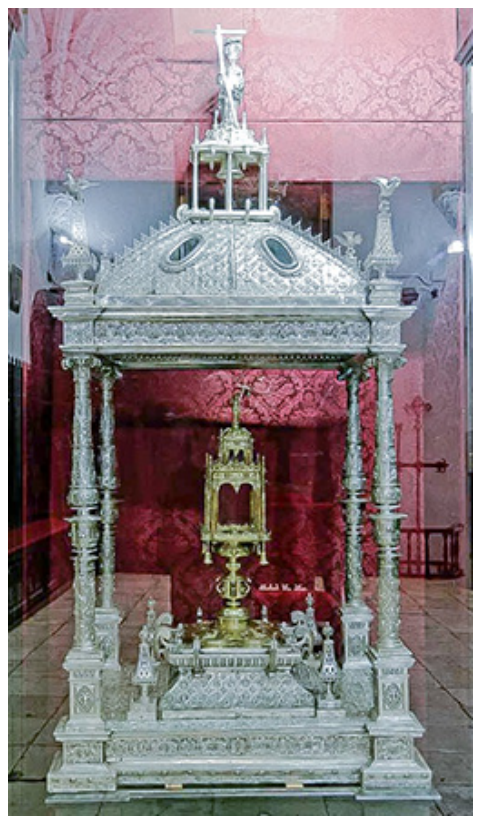

Foto del autor.

\footnotetext{
${ }^{7}$ GUILLAMAS Y GALIANO, Fernando: Historia de Sanhícar de Barrameda, escrita por... Madrid, Colegio de sordomudos y ciegos, 1858, p. 63

${ }^{8}$ Documentadas están, por ejemplo, las dotes económicas que la casa de Medina Sidonia libró de cara a la construcción de los Monumentos efímeros de Semana Santa en 1565, así como el asiento de otras partidas para incentivar la constitución de cofradías sacramentales en el ducado. Véase CRUZ-ISIDRO, Fernando: "Las artes efímeras al servicio de la propaganda de la Casa ducal de Medina Sidonia (1515-1639)", Laboratorio de Arte 27. Sevilla, Universidad, 2015, pp. 87-111.

${ }^{9}$ El estudio sobre la pieza lo aporta SANTOS MÁRQUEZ, Antonio Joaquín: "Un trabajo conjunto de los plateros Juan Tercero y Francisco de Alfaro", Laboratorio de Arte 19. Sevilla, Universidad, 2006, pp. 463-473.
} 
Hasta entonces, las cofradías sacramentales andaluzas -tanto las impulsadas por la dama cortesana, Teresa Enríquez, como las fundadas al amparo de los dominicos y franciscanos- tenían como una de sus funciones básicas la de llevar el viático a enfermos e impedidos de la feligresía o collación. Para ello, el sagrario solía disponerse sobre un altar en alguna de las capillas cercanas a la mayor de cada templo, con la finalidad de no enturbiar las celebraciones que se llevasen a cabo de ordinario. En esa etapa embrionaria, fechable en el primer tercio del siglo XVI, estos altares no revisten de complejidad arquitectónica ni decorativa concreta, basándose en estructuras sencillas que enmarcan, de manera principal, la disposición de un sagrario central ${ }^{10}$.

\section{Las etapas constructivas del espacio eucarístico de Medina Sidonia: promotor inicial, artífice y responsable final}

El desarrollo histórico de las obras de esta capilla sacramental apunta de manera directa a la intervención de tres destacadas personalidades que, en fases y momentos bien distintos, pondrán su interés y talento en pro de la adecuada finalización del proyecto. Entre esas personas, quizás las dos últimas no llegan a coincidir en Medina Sidonia -es probable que no lo hicieran nunca-; sin embargo, las iniciativas que emprenden cada uno de ellos, en función de sus responsabilidades, son entendibles desde el punto de vista de la cooperación de todo trabajo artístico.

El primero de los individuos es el promotor de las obras, probablemente un aún anónimo célibe, encargado de configurar un programa iconográfico que viniese a 'explicar' la honda significación simbólica del espacio resultante. La segunda, el artífice capaz de argumentar a través de las grafías artísticas dichas pretensiones teóricas; tales menesteres van a corresponder al escultor de origen flamenco, Roque Balduque; por último hay que destacar al prelado gaditano de origen cordobés, García de Haro y Sotomayor, empeñado años después en completar el dorado, policromía y estofado de los elementos que componen la máquina 'parlante'. Promotor, artífice y continuador requieren, por sus cruciales intervenciones, de una reflexión previa al análisis de la obra en sí, al objeto de entender con mayor precisión, la finalidad de sus acciones y los motivos que en clave renovadora entendida en una triple dimensión conceptual, plástica y pastoral- les llevan a cada uno a actuar de manera concreta.

${ }^{10}$ GONZÁLEZ TORRES, Javier. Ibídem 


\section{El promotor inicial desconocido: la experimentación iconográfica y simbólica}

Por la configuración y desarrollo final de las obras, este personaje resulta una figura clave. En la documentación contractual consultada no se recoge ni se hace mención expresa a quien debiera haber sido el 'autor intelectual' del proyecto. Cuestión ésta que, siguiendo obras análogas, no recae en la figura del artista, encargado únicamente de plasmar esas ideas previas en elementos plásticos concretos. De hecho, la selección temática realizada y, sobre todo, su incardinación experimental dentro de un programa iconográfico de hondas raíces cristológicas, rebelan que estamos ante una personalidad suficientemente preparada y formada en tales cuestiones.

¿Podría corresponderse con alguno de los canónigos gaditanos existentes en Medina o, por el contrario, sería miembro del cabildo propio de la parroquia, erigida en templo de referencia al amparo de la nobleza? Las respuestas a estas preguntas quedan pendientes de resolución, pero todo hace apuntar que sería una u otra las únicas opciones válidas. Y que, además, esa persona, imbuida del espíritu renovador con el que se caracterizan los años centrales de la centuria del XVI, sería plenamente consciente de la necesidad de plasmar a través del arte conceptos teóricos de compresión compleja; ejemplos parecidos existen, en distintas dimensiones y variadas funciones, a lo largo de la geografía peninsular. Así que tanto por similitud con otras empresas como por 'contagio', tales 'necesidades' pudieron prender en el ánimo de alguno de esos célibes asidonenses, haciéndose responsable final de seleccionar, perfilar y proponer un conjunto de imágenes lo suficientemente impactantes que cumplieran a la perfección con el objetivo previsto: crear un espacio dedicado en exclusiva al culto y la veneración eucarísticas.

En este sentido, la elección de los temas y los personajes incardinados en éstos, deberían cumplir una premisa básica: hacer entendible que un momento concreto de vida de Cristo - la última cena con sus discípulos-, deriva en la institución de la Eucaristía, fuente principal de la que se asienta su Iglesia. En torno a tal cuestión se establecerían dos vías explicativas que redundarían en aspectos concretos de tal significación: de un lado, la propia genealogía del personaje principal; y, de otro, la dimensión histórica y el desarrollo teológicoceremonial que tal actuación concreta supone para la configuración del estamento eclesiástico y su proyección sobre el pueblo de Dios.

La primera de esas líneas temáticas queda resuelta a partir de la iconografía de santa Ana Triple. Un modelo típicamente medieval que se mantendrá en el tiempo -pese a las reticencias trentinas que lo considerarán poco evangélico-, gracias a la fuerte devoción 
popular. La disposición, en una misma pieza y siguiendo un esquema piramidal, de Ana, María de Nazaret y Jesús niño redundan en las leyendas apócrifas instaladas en la mentalidad colectiva que confieren una especial concepción sin mancha a la Madre de Cristo. Un modelo en sí un tanto ambiguo pero en el que los tres personajes ganan en interacción comunicativa con el fiel a partir de atributos concretos: el color verde conferido al manto con el que envolvería la imagen mariana, serviría de alusión directa al concepto de llevar en su seno a 'la esperanza del mundo"11. Significación que quedaría aún reforzada a partir de situar, en el interior del sancta sanctorum, la conocida escena de La Encarnación: María recibe en oración al arcángel Gabriel, quien le hace partícipe de su elección divina como madre del Redentor, revelándole que por obra del Espíritu Santo dará a luz a un hijo.

La segunda línea temática se configura a partir de la incardinación de dos grupos de personajes, claves en el devenir y la configuración jurídico-pastoral inicial de la institución eclesiástica. De un lado, la pareja de los santos Pedro y Pablo; y, por otra, el conjunto conformado por los Padres de la Iglesia: Agustín de Hipona, Gregorio Magno, Ambrosio de Milán y Jerónimo de Estridón. De esta manera el papel de servicio de los apóstoles más cercanos a Jesús a favor de la difusión del mensaje mesiánico de éste, argumentado en pro de la unión de los pueblos en una misma comunidad cristiana, es aceptado por ambos en función de su fe y amor al mesías ${ }^{12}$. Por su parte, el papel detentando por los otros cuatro personajes, a raíz de la legalización de la institución en el siglo IV, supuso un importante acicate de cara al esclarecimiento teológico de creencias y dogmas esenciales. Sus obras, convertidas en textos de referencia para cualquier época posterior, cumplen por ende una función difusora del Evangelio así como conectan con el magisterio eclesiástico más primitivo. Si al dueto de los apóstoles se les confiere el papel de fundamenta Ecclesia, el desarrollado tiempo después por los otros cuatro célibes obedece más bien a la construcción de una estructura de pensamiento básica que, ante polémicas heréticas y encendidos debates en contra, habría de servir de sustento firme tanto para la propia organización religiosa como para sus fieles.

La unión de estas dos temáticas viene dada en función de la disposición del sagrario, situado en el centro del retablo, velado por unas puertas a modo de espacio reservado y, a su vez, separado visualmente del resto del recinto. El motivo obedece a una cuestión trascendental: el cristianismo es una religión revelada cuyo eje principal es la fe en Cristo, poniendo en valor la redención personal de éste a través de su vida, muerte y resurrección.

${ }^{11}$ RÉAU, L., Iconografía del arte cristiano. Iconografía de los Santos t. 2, vol. 3, Barcelona, Del Serbal, 2000, p. 78

12 Mateo 16, 18 
De ahí que un criterio básico de la Iglesia creada en torno a su persona sea el de suscitar entre los creyentes una vida santa a imitación de aquél, mostrando con ello una vocación universal; Cristo es la buena noticia, recogida en los textos evangélicos ${ }^{13}$, que debe ser anunciada para que cada cual, aceptándola de manera libre, haga posible su salvación. Así lo entendieron los apóstoles -en especial, Pedro y Pablo- y continuaron tantos los padres apostólicos como los Doctores de la Iglesia, principales difusores de esa verdad revelada.

La integración de estos personajes históricos en un programa simbólico de base eucarística como el que se pretende desarrollar en Medina Sidonia los convierte, además, en testigos de la presencia permanente y real de Cristo en el sagrario. La comunión de su cuerpo y de su sangre, transustanciadas en el desarrollo ritual de la liturgia, hace recordar al fiel continuamente el sacrificio de aquél en pro de la salvación de la humanidad y el perdón de los pecados. Participar en ese banquete pascual continuado en el que Jesús convida a sus discípulos $-\mathrm{y}$, por ende, a todo cristiano que se acerque hasta el templo para participar del memorial de la pasión-, confiere a sus propias vidas una significación especial, diferenciada: la promesa de unirse a quien ya disfruta, según sus propias palabras, de la vida eterna.

$\mathrm{Y}$, de igual manera, existe en este proyecto unitario un componente que va más allá de lo social. De hecho, la disposición de los dos temas marianos anteriormente mencionados se incardina, a su vez, con la actitud militante de los padres apostólicos. A partir de dichas referencias se pretende potenciar la naturaleza humana y divina del protagonista, un dogma que quedaría establecido en el Credo niceno-constantinopolitano, promulgado en 381, y sobre el que se fraguarían con posterioridad distintas fundamentaciones teológicas. La unión de la deidad y la humanidad de Cristo en una sola persona lo identifican, en su carácter popular, con los propios fieles que padecen, al igual que él, penurias, dramas y tragedias diarias. Participar por lo tanto de la comunión con Jesús, conlleva para éstos la experiencia misma de la vivencia sacramental; para ello es necesario reconocer los gestos y símbolos que rodean el sacramento eucarístico, incardinados en el rito litúrgico.

Semejantes criterios, de hondo contenido teológico-sacramental, no son novedosos en cuanto a su argumentación teorética pero sí conforme a su plasmación y concreción en un programa iconográfico que trate de poner de relieve tales significados. Éstos serán debatidos y reafirmados por el Concilio de Trento en fechas paralelas y posteriores a la ideación asidonense; de ahí el carácter experimental con que se pretende imbuir el espacio simbólico resultante, absolutamente pionero en el ámbito de la arquitectura religiosa andaluza

${ }^{13}$ Cfr. con las palabras de Cristo resucitado a sus discípulos, recogidas en Marcos 16, 15-17: "Id por el mundo entero propagando la buena Noticia”. 
y a la vanguardia de los debates pre y post-trentinos. Para llevar a la práctica tales principios debía recurrirse a un artista de cierta solvencia práctica, capaz de traducir en imágenes esos conceptos complejos y, a su vez, adecuarlos a un marco arquitectónico en el que actuasen de agentes complementarios al elemento fundamental: el receptáculo sacramental.

\section{Un artífice a la vanguardia del arte religioso: Roque Balduque}

El segundo de los protagonistas es el escultor flamenco Roque de 'Baldoc', 'Bolduque' o 'Balduque"14. La imprecisión con la que se cita su apellido en la documentación de archivo procede de la latinización del topónimo de su ciudad de origen, Bois-le-Duc, capital de Brabante, al sur de Flandes. La fecha de su nacimiento sigue siendo otra de las incógnitas que se ciernen sobre el personaje, estando fechada su estancia en Sevilla por vez primera en 1534. Pese a tales dudas, estamos ante una de las personalidades más interesantes del panorama artístico andaluz del primer tercio del siglo XVI y uno de los 'culpables' del cambio de gusto de la clientela en la confección de retablos. De hecho, su prolija labor como entallador y escultor le permite competir, tipológicamente hablando, con los hasta entonces habituales paneles pictóricos en los que se articulaban los ciclos pictóricos; la sustitución de éstos por plafones en relieve y/o esculturas exentas permiten una variable visual mucho más impactante: la fuerza de la imagen corpórea otorga rotundidad al mensaje que subyace en las representaciones escultóricas.

Pero no queda solo en eso. Otra aportación fundamental deviene de unir el bagaje estético adquirido durante su aprendizaje/formación y la asunción de criterios más novedosos, experimentados en plena madurez. Una equilibrada apuesta entre lo antiguo y lo moderno que, al igual que otros artistas coetáneos, recorre el sentido más naturalista de la escultura gótica para enlazarla con las novedades formales del Quattrocento italiano. De ahí que la presencia de elementos medievales, de gusto popular, queden emparentadas con soluciones clasicistas procedentes del mundo del grabado. Distintas y difundidas escenas firmadas por los punzones de Alberto Durero o Marco Antonio Raimondi constituyen una

\footnotetext{
${ }^{14}$ Resultan básicos los estudios de: GESTOSO, José: Ensayo de un diccionario de los artífices que florecieron en Sevilla desde el siglo XIII al XV III inclusive, t. III. Sevilla, La Andalucía Moderna, 1908, pp. 91-95; ESTELLA MARCOS, Margarita: "Nota sobre la escultura sevillana del siglo XVI", Archivo Español de Arte vol. XLVIII. Madrid, Instituto de HistoriaC.S.I.C., 1975, pp. 225-242; BERNALES BALLESTEROS, Jorge: "Esculturas de Roque Balduque y su círculo en Andalucía y América", Anuario de Estudios Americanos XXXIV. Sevilla, C.S.I.C., 1977, pp. 349-371; y PALOMERO PÁRAMO, Jesús Miguel: El retablo sevillano del Renacimiento. Sevilla, Diputación, 1983, pp. 134-159. Los datos biográficos y los referidos tanto a la particular maniera desarrollada por el artista flamenco como a obras concretas, proceden de éstos.
} 
fuente iconográfica de primer orden, motivo de inspiración para personajes, gestos o ambientaciones.

En cuanto al uso de un catálogo de formas arquitectónicas, necesarias para construir las líneas estructurales básicas sobre las que configurar los retablos, Balduque alude a ejemplos flamencos de décadas anteriores. Destacan en este sentido la reutilización de arcos carpaneles siguiendo la estela desarrollada por Juan de Juni; la disposición de cariátidescolumna, rematadas en su parte superior por capiteles de reminiscencias jónicas, al modo de las utilizadas en la producción de Esteban Jamete; o el gusto flamenco por la disposición de arcos abocinados y artesones ochavados, en un intento de dotar de profundidad a hornacinas, veneras o nichos. Elementos que, a su vez, sirven de soporte a repertorios ornamentales inspirados en grabadores europeos, destacando el desarrollo del grutesco y la decoración $a$ candelieri como referencias de absoluta modernidad.

La continuada revisión de estos planteamientos estético-formales en un período donde los comitentes requieren de soluciones artísticas ante determinadas cuestiones litúrgicas, embarcan a Balduque en una prolija actividad al servicio de clientela eclesiástica. Especial mención requieren los trabajos desarrollados en Extremadura y la Baja Andalucía, sin desdeñar otras actividades vinculadas al mercado americano. El análisis comparativo de las labores llevadas a cabo permite diferenciar cuatro tipologías de retablos, construidos a partir de características concretas: las grandes máquinas de tres cuerpos y tres calles; los tabernáculos marianos insertos en sencillos esquemas constructivos; el altar-relieve presidido por una escena de considerables dimensiones; y, las estructuras arquitectónicas que, enmarcando en tres calles y ático, sirven de soporte idóneo para tableros pictóricos.

A partir de estas cuestiones, la figura de Balduque se torna en fundamental. Máxime cuando en Sevilla, al compás de la bonanza económica y dentro de un ambiente cultural en el que descuella su flamante Universidad, logra constituirse un prolífico elenco de artistas capaces de seguir la estela flamenco-italiana y aportar recursos estéticos, iconográficos o formales novedosos. Los italianos Pietro Torrigiano y Domenico Fancelli, los franceses Miguel Perrin y Nicolás de Lyon así como el germano Jorge Fernández Alemán, son algunos de los artífices que a principios de siglo llegan a la capital hispalense atraídos por las obras de la Catedral. Coetáneo a Balduque es el salmantino Juan Bautista Vázquez 'el Viejo', figura que cierra el ciclo de creadores-renovadores del momento ${ }^{15}$.

${ }^{15}$ Director de un extenso taller -entre cuyos miembros se encuentran Juan de Oviedo, Miguel de Adán, Gaspar del Águila o Jerónimo Hernández-, establece unas pautas estilísticas comunes que son ampliamente desarrollada por sus colaboradores. Criterios que de igual manera emulan otros artistas vernáculos, preludiando 
Su elección como artífice de la capilla medinense es fruto de la propia historia constructiva del recinto sacro en el que ésta se incardina: en 1551 quedan contratadas las trazas y primeras tallas del monumental altar de la capilla mayor parroquial, cuyas labores de ornato habían quedado paralizadas tras no continuarse las pactadas en 1533. Aquellas primeras escenas en relieve que Balduque firmara, debieron impactar fuertemente a las dignidades del templo, entendiendo que estaban ante la persona más idónea para llevar a cabo el complejo proyecto simbólico.

\section{E1 responsable final las obras: García de Haro, un prelado estratega}

El tercero y último de los actores de referencia es un personaje fascinante: García de Haro y Sotomayor Portocarrero. Pese a las lagunas que aún plantea su escasamente estudiada biografía, las escuetas referencias trazan el perfil de un noble nacido en la década de 1520, de formación militar en su adolescencia, preocupado en su madurez por el carácter evangélico inherente al oficio de pastor diocesano. Una idea que deviene del impulso dado a las empresas que encabeza y de la implicación personal que ejerce sobre las mismas, demostrando siempre una fuerte personalidad. Del estudio de sus acciones se deduce que éstas son propias de un intelectual, dotado tanto de una preclara mentalidad como de unos conocimientos artísticos avanzados ${ }^{16}$.

Es, a su vez, un personaje fiel a su tiempo. Formado probablemente en el colegio de jesuita de santa Catalina, de Córdoba, y conocedor en primera persona del proceso de renovación teológica en el que está inmersa la Iglesia en general y, en particular, la cordobesa, su adolescencia coincide con el contexto histórico inmediatamente anterior al de la Renovación católica. En este sentido, el carácter nobiliario de su familia le habría permitido ser testigo de la doble dimensión eclesiástica con que se caracteriza la primera mitad del siglo XVI: entre el impulso devocional desarrollado por los prelados de las décadas iniciales y el espíritu reformista que se proyectará en las siguientes, amparado por la normativa de obligado cumplimiento establecida por el Concilio de Trento. Es justamente en esos momentos, donde el culto eucarístico vuelve a ser el centro de las celebraciones litúrgicas para así responder a una doble cuestión: la crítica luterana, que ponía en cuestión las doctrinas

así el comienzo de un nuevo ciclo para la escultura sevillana, el del proto-Barroco, convertida por méritos propios en idiosincrático círculo de escultura.

16 Próximamente publicaremos un artículo dedicado exclusivamente a esclarecer algunos puntos de su biografía así como a analizar los aspectos más significativos de su personalidad y oficio. Lleva por título Las prelaturas andaluzas de García de Haro: claves biográficas y pastores de un obispo reformista del siglo XVI. 
teológicas sobre la transustanciación y, de paso, la revitalización del mensaje mesiánico esencial que da origen a la propia religión cristiana.

Aspectos que, de igual manera, quedan reflejados en cada uno de los sínodos diocesanos que, tanto en época anterior, como durante el Concilio y fechas siguientes, tratan de reformar las prácticas cultuales y litúrgicas para adaptarlas a esa nueva mentalidad; se trata de una normativa de conjunto, aplicable a cualesquiera demarcación diocesana ${ }^{17}$, mediante la cual se planteen prohibiciones concretas, se eliminen prácticas entendidas como abusivas o se suplen carencias en pro de una mayor ejemplaridad de los ritos y la eficacia de los efectos 'positivos' que redundan sobre el fiel ${ }^{18}$.

Volviendo a la persona en cuestión, el 24 de noviembre de $1562^{19}$, García de Haro es nombrado archimandrita de Mesina, ostentando de esta manera una dignidad eclesiástica siciliana de primer orden ${ }^{20}$. Sin embargo, apenas transcurren dos años después, el 25 de octubre de 1564, el papa Pío IV lo designa obispo de Cádiz, dando traslado de su decisión a Felipe $\mathrm{II}^{21}$. El documento pontificio [Imagen 3] otorga validez canónica al acuerdo particular al que ha llegado el religioso cordobés con quien desde 1523 ocupa la prelatura gaditana, Jerónimo de Lorenzo Theodoli; consiste en traspasar dicha dignidad ad personam a favor de García de Haro quien, a tenor de sus méritos, queda preconizado a todos los efectos como prelado de Cádiz.

Con tal nombramiento se podría fin a la larga lista de obispos de origen italiano que, desde 1495, se habían ido sucediendo en la diócesis gaditana. Los inicios en el nuevo oficio no van a ser fáciles, enfrentándose por ejemplo a las particulares atribuciones que se habían auto-asignado los canónigos aprovechándose de las dejaciones del anterior pastor. Un pleito

\footnotetext{
17 GONZÁLEZ TORRES, Javier: "Las constituciones sinodales andaluzas de los siglos XVI y XVII. Dimensión social y trascendencia historiográfica como fuente legislativa para el estudio del arte eucarístico", Norba. Revista de Arte 37. Cáceres, Universidad de Extremadura, 2017, pp. 141-163.

${ }^{18}$ En este sentido, las siete sesiones sinodales que, entre mayo de 1563 y abril de 1570, se celebrarán la diócesis cordobesa convocados por el obispo Rojas y Sandoval, no hacen más que refrendar tales propósitos que, además, alcanzan una dimensión extraordinaria cuando se refieren al sacramento eucarístico. Véase HERRERA MESA, Pedro Pablo: "El tema eucarístico en los sínodos cordobeses del obispo Rojas y Sandoval (1563-1570)", en AA.VV., Actas del Simposio Religiosidad y ceremonias en torno a la Eucaristía vol. 1. El Escorial, I.E.I.H.A., 2003, pp. 353-370.

${ }^{19}$ En SALTILLO, Marqués del: "El patronato de Castilla y la presentación de Diócesis en tiempos de Felipe II (15731598)", Boletín de la Real Academia de la Historia t. CXXIII, cuaderno II. Madrid, 1948, p. 480, se cita a García de Haro con tal dignidad, aludiéndose al documento real que así lo acredita. Éste ha quedado felizmente localizado en el Archivo Histórico Nacional, Sección Consejos, Libros de Iglesia (I-X), (1556-1618), lib. 2735, fols. 21 al 67. ${ }^{20}$ MORONI ROMANA, Gaetano: Dižionario di erudizione storico-ecclesiastica vol. II. Venecia, Tipografia Emiliana, 1840, pp. 275-276.

${ }_{21}$ Archivo General de Simancas, PTR, leg. 60, doc. 134. El documento, desde el punto de vista del Derecho canónico, es un rescripto; es decir, recoge por escrito un acto administrativo que firma la autoridad ejecutiva y que, por su naturaleza jurídica, concede un privilegio, una dispensa u otra gracia, respondiendo siempre a una petición formulada con anterioridad.
} 
que se enquistaría en el tiempo y que le llevará incluso hasta trasladarse a Roma en dos ocasiones, tomando decisiones contundentes contra el deán y prebendados, así como enfrentándose al Nuncio apostólico, Felipe Sega ${ }^{22}$. A pesar de estas dificultades, en las que dio muestras de su exaltado espíritu - consecuente con su pasado militar-, la prelatura gaditana de Haro se extiende hasta 1587, fecha en la que será promovido a obispo de Málaga.

\section{Imagen 3}

Bula pontificia de nombramiento de García de Haro como obispo de Cádiz, firmada por el papa Pío IV (25.10.1564). Archivo General de Simancas.

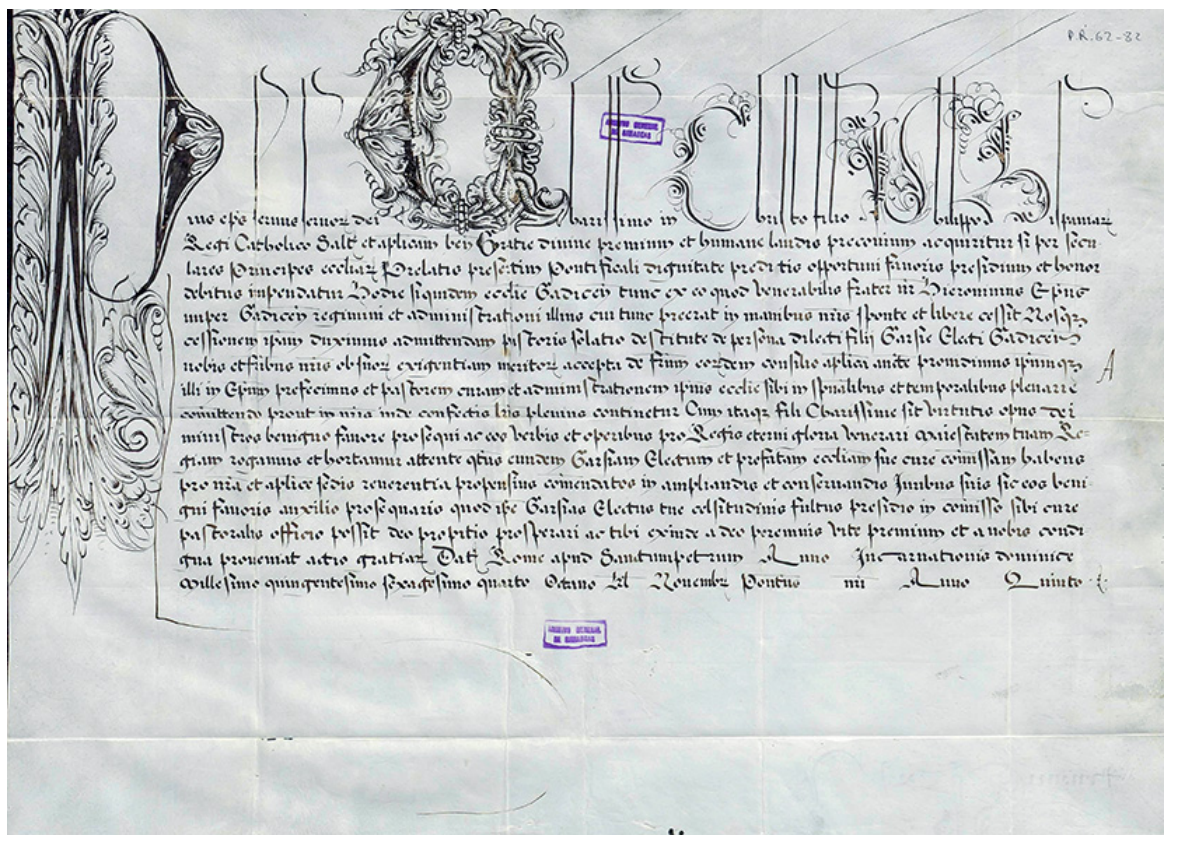

Foto del autor.

Su papel en la empresa asidonense no es baladí. Convencido del papel reformista que debe desarrollar todo prelado post-trentino, ordena culminar las obras del retablo. Éste no es, además, un proyecto cualquiera. Los conocimientos teológicos que Haro posee le hacen ser consciente de estar ante un reto importante: una capilla dedicada por completo al culto eucarístico no puede permanecer, por más tiempo, inacabada. Sus órdenes al respecto son claras y tajantes; de hecho, van más allá de un mero impulso derivado del proceso histórico de renovación que vive la Iglesia. Tal impacto provoca en él el programa iconográfico planteado que, años después y ostentando ya la prelatura malacitana, ordenará la ejecución

22 MORGADO GARCÍA, Arturo: “Los inicios de la Reforma católica en la diócesis de Cádiz”, en Espacio, Tiempo y Forma, serie IV, Ha. Moderna, t. 7. Madrid, UNED, 1994, pp. 101-120 y FERNÁNDEZ COLLADO, Ángel: Gregorio XIII y Felipe II en la Nunciatura de Felipe Sega (1577-1581). Aspectos político, jurisdiccional y de reforma. Toledo, Estudio Teológico de San Ildefonso, 1991, pp. 262-268. 
de otro de características similares -aunque mucho más elaborado- para la capilla mayor de la catedral de Málaga. Así, estamos ante una obra crucial no solo por su significado simbólico sino, también, por servir de referente iconográfico para iniciativas posteriores.

\section{3. ¿La primera capilla sacramental andaluza? Proyección artística y trascendencia histórica}

El 22 de enero de 1554 se concierta con Roque Balduque la decoración del retablo sacramental de la parroquia de Medina-Sidonia; lo hace en nombre de ésta el clérigo y mayordomo, Hernán Ximénez. El compromiso del artista flamenco consiste en labrar sagrario y retablo ad hoc, ateniéndose a las siguientes condiciones en cuanto a su volumen ${ }^{23}$ : el conjunto ha de disponerse entre los dos pilares formeros de la capilla, estante al final de la nave del Evangelio; en cuanto a la altura, el armazón debe ocupar desde el suelo hasta el entablamento, elemento que divide la superficie muraria del arranque de los arcos nervados/apuntados que conforman una semibóveda estrellada.

En el centro de la estructura se abrirá una puerta de 9 palmos de alto y 4 de ancho, es decir, de unos 2x1 metros, en cuyo casetón central, circular, quedaría inscrito un relieve de Santa Ana triple. Así se cerraría exteriormente el pequeño recinto resultante, que haría las veces de Sancta sanctorum y en cuya pared del fondo quedaría instalado el tabernáculo sacramental; sobre éste, un relieve del arcángel Gabriel saludando a María de Nazaret, escoltado por dos ángeles y dos florones tallados entre conchas de media talla. El resto del conjunto quedaría proporcionado conforme a la estancia central, cerrada y escoltada por dos pilares monumentales sosteniendo un arquitrabe. De esta forma, la estructura arquitectónica resultante habría de servir de soporte a una de las escenas claves en el discurso iconográfico: la de Jesús y los doces apóstoles en el momento de la institución de la Eucaristía. Completarían el mensaje final en el piso bajo y en el superior las esculturas de los santos Pedro y Pablo así como las de los cuatro Doctores de la Iglesia, no especificándose su disposición [Imagen 4]. La madera escogida para la elaboración de estos elementos es el borne de Flandes, labrándose conforme a los modelos que adjunto a la escritura debieron presentarse -hoy desconocidos-. Queda estipulado el montante económico en 110.000 maravedíes, estableciéndose su elaboración 14 meses a contar desde la firma del contrato.

${ }^{23}$ GESTOSO, José: op. cit., p. 42. El historiador hace referencia a un documento estante en el Archivo Histórico Provincial de Sevilla con la signatura Of. 20, lib. I de 1554, fol. 229. Comprobada la misma en mayo de 2016, ésta no se corresponde con legajo alguno. Nos ceñimos pues a la transcripción publicada. 


\section{Imagen 4}

\section{Serie de los Doctores de la Iglesia. Roque Balduque (1554-1559).}
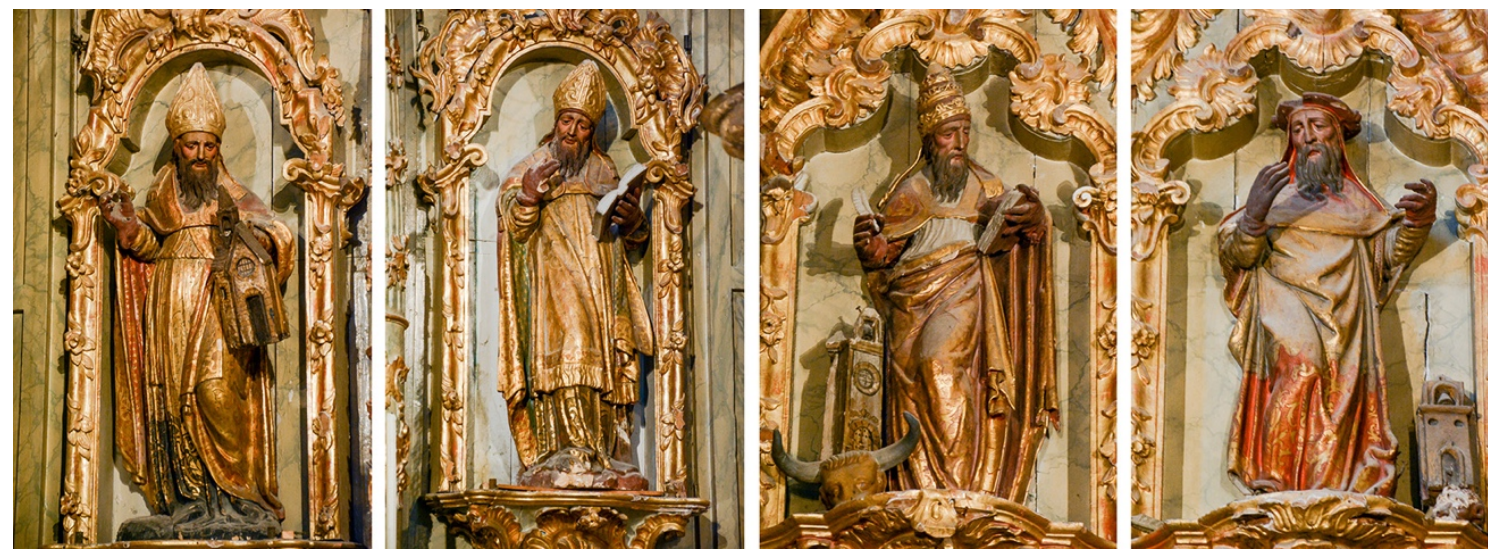

Foto del autor.

Empero los procesos debieron demorarse más de lo previsto puesto que, cinco años después, el 2 de mayo de 1559, Balduque no había concluido el encargo. Es más, el mayordomo asumía la entrega de 60 ducados -no sabemos si como sobrecoste o si, por circunstancias, se había incumplido algún pago- al objeto de culminar los Doctores y al menos cuatro de los discípulos, incluyéndose una nueva imagen exenta, no especificada [Imagen 5]. Pudo también deberse el retraso a las tallas que el flamenco tenía contratadas para el retablo de la capilla mayor y que en la citada fecha aumentó en 14 relieves ${ }^{24}$.

El caso es que en 1575 el retablo eucarístico estaría concluido en cuanto a talla y escultura, restando su dorado y policromía ${ }^{25}$. Siguiendo las directrices conciliares, los prelados están obligados a establecer cuantas visitas canónicas sean necesarias para conocer, bien de primera mano o a través de provisores, el estado de las parroquias, iglesias y demás recintos sacros de sus diócesis. Al respecto, el obispo de Cádiz, García de Haro, debió tener conocimiento de la situación de provisionalidad en la que se encontraba este retablo eucarístico por lo que ordenaría, a tenor de las indicaciones pastorales en torno al culto sacramental y de la trascendental función que cumplía dentro del ceremonial litúrgico cotidiano, culminarlo de la mejor forma ${ }^{26}$.

\footnotetext{
24 PALOMERO PÁRAMO, Jesús Miguel: op. cit., p. 138-141.

${ }^{25}$ No ocurriría lo mismo con el de la capilla mayor, para el que García de Haro contrata, a través del mayordomo parroquial, los servicios escultóricos de Juan Bautista Vázquez ‘el Viejo’ y Melchor Turín.

${ }^{26} \mathrm{El}$ obispo ejemplifica el comienzo de la Reforma en Cádiz. Con su determinación, dejaba atrás los años de dejadez al optar por soluciones contundentes y necesarias. Así ocurre con la remodelación que él mismo propone para la cabecera de la catedral vieja, modificando los pilares estructurales y trasladando el coro de lugar. Cfr. MORGADO GARCÍA, Arturo: La diócesis de Cádiæ: de Trento a la desamortización. Cádiz, Universidad, 2008, pp. 26 y ss.
} 


\section{Imagen 5}

Santo Tomás de Aquino. Roque Balduque (1554-1559). Es posible que una de las tallas concertadas en el segundo contrato con el autor flamenco se trate del Doctor Angélico, toda vez que es el autor del oficio litúrgico del Corpus. Su presencia en el programa habría de entenderse como una continuación cronológica del activismo de los primeros apóstoles y las apologías de los Padres de la Iglesia; la actuación del dominico, en época medieval, supone la redefinición del concepto de 'presencia real' de Cristo en el sacramento eucarístico así como el comienzo de una serie de prácticas cultuales que están en la base de posteriores costumbres, propias de la piedad popular.

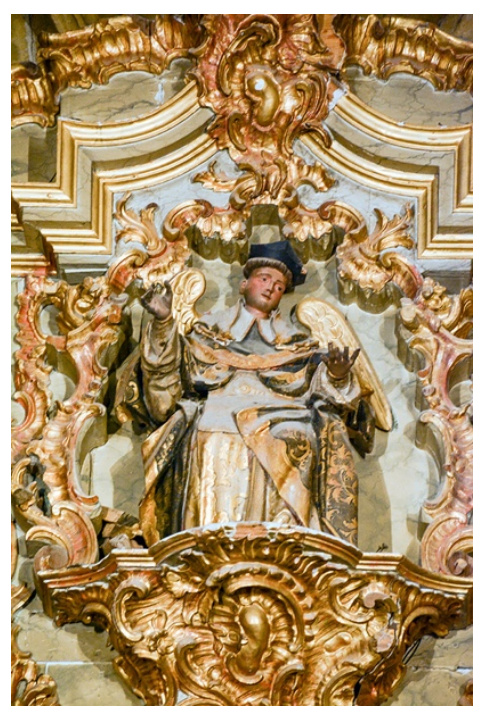

Foto del autor.

$\mathrm{Al}$ respecto es clave el contrato hasta ahora inédito ${ }^{27}$ que vincula las labores restantes al sevillano Miguel Vallés, en un primer momento y, al jerezano Antonio de Arneda, en un segundo, quienes se comprometen a dorar toda la máquina [Imagen 6]. El interesante documento es clave en un doble sentido: tanto porque a lo largo de su redacción se hace mención expresa a cada uno de los elementos escultóricos labrados por el artífice flamenco como, también, porque tras las nuevas labores está presente la mano del prelado cordobés; es más, éste va a encargarse de apostillar que el proceso contaría con su personal seguimiento para, a la postre, aprobar o desestimar el resultado final.

\footnotetext{
27 AHPS, Sección Protocolos, Oficio XIX de Gaspar de León, Libro 5 de 1575 / Legajo 12428, fol.183v. Es de justicia agradecer vivamente al prof. dr. Jesús Miguel Palomero Páramo la deferencia que ha tenido en facilitarnos tal documentación, así como por ofrecernos una serie de datos complementarios de vital importancia para el desarrollo del presente estudio.
} 


\section{Imagen 6}

\section{Primera página del contrato de 1575 entre los doradores Vallés y Arnedo con el mayordomo de fábrica, Buiza, para la realización de las tareas de dorado, policromado y estofado del retablo sacramental. Archivo Histórico Provincial de Sevilla}

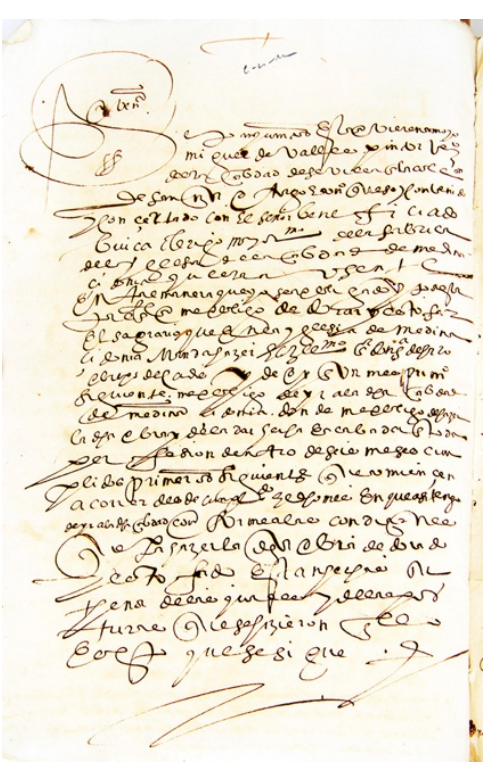

Foto del autor.

En esta ocasión, es el beneficiado y mayordomo de la fábrica parroquial, Buiza, quien ejerce de contratista actuando por orden del prelado. El primero de los doradores entiende que las labores a realizar no deben ocuparle más de seis meses; si bien reconoce que, antes de su comienzo, debería acudir hasta Medina Sidonia para inspeccionar la situación de la obra. Suponemos al respecto que el lapso de tiempo entre la finalización de las labores anteriores y el comienzo de estas nuevas jugaría en contra del estado de las maderas, encontrándose éstas vivas, sin aparejo y desprovistas de cualquier tratamiento conservativo. De ahí que, como solía ocurrir en trabajos similares, Vallés debió subcontratar los servicios de otro compañero de profesión, vecino de la localidad asidonense, para que procediese a tal comprobación. Es así como se explica que, a partir del folio siguiente del contrato, sea Arneda quien desglose en quince capítulos el trabajo a realizar, haciendo un repaso pormenorizado de procedimientos, técnicas y recursos que serían de aplicación.

$\mathrm{Al}$ respecto, el documento ofrece una certeza absoluta sobre la ejecución total de lo contratado en 1554, describiendo cada sección de manera pormenorizada. Así ocurre con los elementos tectónicos, detallándose arquitrabes, columnas, capiteles, artesones, pedestales, remates, molduras, veneras, arcos o zaquizamíes. De igual manera, se deja entrever el estado 
alla prima de la madera del conjunto, a la que se debe aplicar "capas de engrudos delgados hechos de buen retaço y dado de su yeso mate, después ya dado de bol como comviene a buena obra”. El análisis de Arneda le lleva incluso a especificar los procedimientos de dorado y estofado a aplicar en ciertas partes, como las columnas, cuyos "campos sean metidos en blanco o azul o colorado como mejor convenga", mientras que las que no estuvieran demasiado talladas, "sean estofadas y los campos granydos de buen punto y los capiteles sean estofados lo que fuere menester".

Mención especial requiere el tratamiento pictórico que debe aplicarse a las esculturas. El detallismo en cuanto al resultado final que han de ofrecer tras aplicarse el mismo es absoluto. Así, para el protagonista del relieve central, el de la Cena de Cristo y sus discípulos, "después de dorado", su vestidura debiera "estofarse de morado", mientras que cada uno de los doce apóstoles se entonarán en "diversos colores y labores con muy buena grazia" [Imagen 7]. De la misma manera se ha proceder con "los Doctores con sus ynsignias: san Agustín, de prieto y blanco; san Jerónimo, de colorado; san Gregorio, [...] vestido de pontifical; y, san Ambrosio, de brocado de colores diferentes”. Las cabezas de todos ellos quedan ceñidas con "mitras con sus perlas y piedras". En referencia al conjunto de ángeles y serafines que debían pulular por todo el panel lignario, "los rostros y carnes y pies y manos sean encarnados de encarnación polida, hechos [...] sus cabellos abiertos, sus ojos y uñas [...] de oro mate".

\section{Imagen 7}

\section{Sagrada Cena. Roque Balduque (1554-1559)}

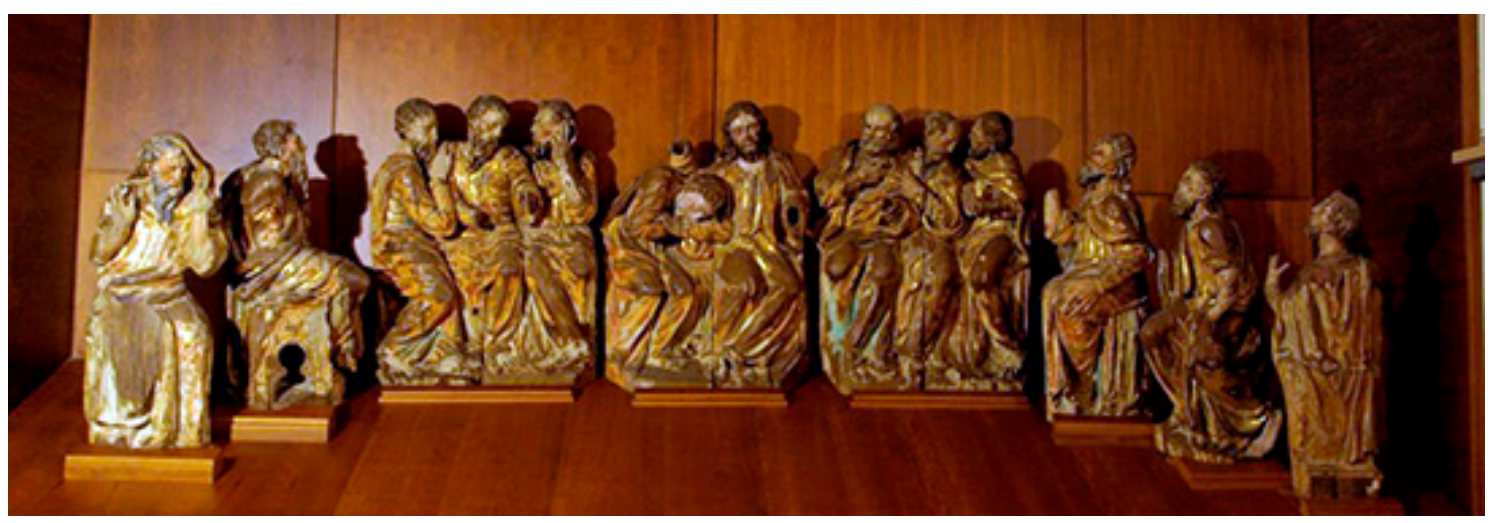

Foto del autor.

Se permite también en el documento una apostilla artística a criterio del dorador. Y es que si éste entiende que, a pesar de todo lo anterior, "alguna cosa en estas dichas condiciones faltare, a lo hazer como sy estuviese puesto" en las mismas, "sin demandar otro 
premio alguno por ello”. Es decir, el profesional tendrá que completar aquello que no haya especificado a partir del procedimiento técnico que estime más conveniente, sin que por ello obtenga remuneración económica alguna. De hecho, la terminación del conjunto debe cuidarse por completo, indicándose de manera expresa que ha de emplearse siempre "oro bruñido fino", dejándose el pan de plata solo "si en algunos casos fuera menester para darse de carmesí o trasflorar de otro color".

Culmina el protocolo con otra apostilla más: la de las visitas que podría realizar el obispo García de Haro durante el desarrollo de estas labores para así comprobar, de primera mano, el estado de las mismas y el cumplimiento de lo acordado. En este sentido, "una vez acabado el dicho Sagrario", el prelado nombrará a tres oficiales "hábiles y suficientes”, para que "declaren si la dicha obra está acabada conforme a buena obra y a las dichas condiciones para habiéndose acabado conforme a como está obligado". En caso que no responda el resultado final a los criterios plasmados en el contrato, el artista solo cobrará por aquello que, a tenor de los revisores/censores, sea digno de pago. Queda así constancia de un procedimiento de tasación obligatoria, ligado al progreso correcto del proceso creativo, que no tendría porqué hacerse a la terminación de éste sino en cualquier momento que se considerara oportuno por los contratantes.

Finalmente, los trabajos que al comienzo se previeron desarrollar en seis meses, a partir del informe relatado pasarán a un año y medio, sufragándose el montante total en tres plazos a contar desde el comienzo y hasta la finalización. Es igualmente curioso comprobar el afán del obispo de Haro por dejar patente su interés en la más que correcta aplicación de recursos netamente estéticos o en la concretización de aspectos iconográficos; disposición que va a convertirse en una constante a lo largo de su trayectoria cada vez que, en su nombre o por mediación de él, se contraten obras de arte ${ }^{28}$. Así que, antes de 1577 , todo el conjunto estaría ultimado y, por interés especial de comitente y artífices, de manera correcta.

\section{El devenir histórico trunca el experimentalismo inicial}

El 12 de abril de 1773, un terremoto con epicentro en Tarifa se hace sentir en toda la comarca de la Janda, viéndose afectadas numerosas construcciones. No es ajena al seísmo

\footnotetext{
28 Véase al respecto el contrato que años después, ya como obispo de Málaga, establece con Cesare Arbassia para los frescos y demás elementos pictóricos de la capilla mayor de la Catedral (Archivo Histórico Provincial de Málaga, escribanía de Bernardino de Escobar, leg. 526, años 1588-1589, s/f). La transcripción y el estudio del mismo en SÁNCHEZ LÓPEZ, Juan Antonio: "Non Vos Delerinquam. La Catedral de Málaga y un sueño del Renacimiento", Espacio, Tiempo y Forma serie VII, t. 6. Madrid, U.N.E.D., 1993, pp. 221-240.
} 
Medina Sidonia, cuya Parroquial mayor se ve enteramente dañada, sin que se cuantificaran las pérdidas con exactitud o se especificaran los desperfectos concretos. Lo que sí se conoce es que debió perjudicar al retablo eucarístico, procediéndose en los meses siguientes a una remodelación profunda de sus estructuras lignarias y al acople tanto de molduras como golpes de talla en rocalla.

De igual manera, entre 1868 y 1870 se procede a una nueva modificación [Imagen 8], reconfigurándose sus elementos tectónicos y perdiéndose para siempre algunos de los que seguramente conformaron su estructura primitiva ${ }^{29}$. En cuanto al programa iconográfico, se adosaron a la nueva estructura pero en un sentido distinto al primitivo los cuatro doctores de la Iglesia y la representación individual de santo Tomás de Aquino; tras dichas actuaciones, fueron desubicados el grupo de La Cena ${ }^{30}$, el de Santa Ana triple ${ }^{31}$ y los santos Pedro y Pablo ${ }^{32}$. Tales actuaciones obedecen a su vez a una concepción de la estética religiosa diferente a la configurada en los albores de la Reforma católica así como a la necesidad de dotar de un nuevo sentido simbólico al espacio resultante, cuyo mensaje final termina siendo un tanto ecléctico. A éste se incorpora un sagrario marmóreo de reducidas dimensiones, cerrado con una puerta de plata, así como un argénteo frontal de altar; ambas piezas son de autoría mexicana, labradas en el siglo XVIII.

Acabaría así, de manera completamente desgraciada, la historia de un retablo pionero y excepcional que va a marcar, casi sin pretenderlo, un importante camino en la arquitectura religiosa andaluza de los Siglos de Oro. La experimentación del espacio sincrético donde se custodiaba el tabernáculo de reminiscencias hierosolimitanas ${ }^{33}$, la disposición de un programa escultórico en torno a la Eucaristía y su relación con personajes concretos, la disposición de un altar sacramental desligado de la capilla mayor, el interés de los artistas por llevar a cabo una obra en la que se verifiquen expresamente los deseos de los promotores, el celo del prelado de Haro en hacer cumplir las disposiciones contractuales o el aire de extraordinaria vanguardia teológico-simbólica que se encierra prácticamente en las fases constructivas, son algunas de las cuestiones que las circunstancias materiales borraron del imaginario colectivo pero que la memoria documental y archivística encierra, para siempre,

${ }^{29}$ El Sancta santorum dio paso a un camarín sobreelevado, abierto sobre el muro de cierre de la capillla, que bien podría haberse labrado en la transformación llevada a cabo a finales del XVIII. En el mismo quedaría depositada la imagen de la Virgen de la Paz, proclamada patrona de la villa por Bula de Pío VIII (20.08.1802) y que hasta entonces se veneraba en el convento de san Agustín.

30 Restaurado entre 1992 y 1993 por técnicos del IAPH, a la espera de su exposición en el museo parroquial.

31 Depositado en el cercano convento de Jesús, María y José, tras pasar por varias ubicaciones.

32 En paradero desconocido.

${ }^{33}$ Relacionable, desde lo conceptual, con las obras que a partir de 1578 se llevarán a cabo en la mezquita-catedral de Córdoba para adecuar en sus naves la capilla del Sagrario; el proyecto, de base humanista, trata de reproducir esquemáticamente las partes esenciales del mítico Templo de Salomón. 
en legajos y contratos. En ellos está la clave para interpretar, correcta y adecuadamente, la historia de las mentalidades y su proyección sobre el arte.

\section{Imagen 8}

Estado actual de la antigua capilla sacramental de la parroquia de santa María La Coronada, de Medina Sidonia (Cádiz).

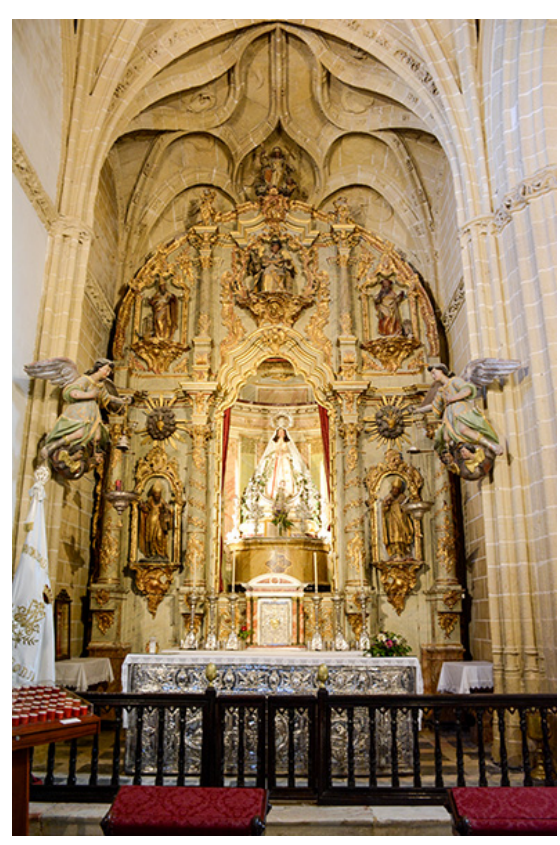

Foto del autor 